\title{
Screening of Nasal MRSA Carriage among Health Care Workers at a Tertiary Care Centre in Chhattisgarh at Rajnandgaon District
}

\author{
Kausar Rawani and Siddharth Pimpalkar* \\ Department of Microbiology, Govt. Medical College, Rajnandgaon (C.G.), India \\ *Corresponding author
}

\begin{abstract}
A B S T R A C T
Staphylococcus aureus is recognized as an epidemiologically important nosocomial pathogen. Staphylococcal infections are frequent in hospitalised patients despite antibiotic therapy (e.g. MRSA) and these patients may have severe consequences. The ecological niches of S.aureus are anterior nares (primary reservoir), skin, mucosal surfaces. HCWs constitute an important reservoir of S. aureus. Nasal MRSA carriage is a recognised risk factor for subsequent infection of endogenous origin. So, the present study was planned to determine the prevalence of nasal carriage of MRSA among HCWs. The cross sectional study was conducted in Government medical college, Rajnandgaon, Chhattisgarh India during study period from july 2018 to October 2018 on 100 HCWs. Procedure was performed as per standard microbiological techniques. Data was then compiled in MS Excel and statistical tests were applied. It was found out that the prevalence of nasal carriage of S.aureus was $21 \%$. Out of which $61 \%$ were MRSA. The prevalence among nurses, doctors, lab technicians, class IV workers were $22.85 \%, 0 \%, 10 \%, 20 \%$ respectively. It can be concluded that the prevalence of MRSA is huge among nurses. Awareness regarding simple preventive measures, judicious use of antibiotics, treatment using $2 \%$ mupirocin nasal ointment and periodic screening to identify carriers can help reduce transmission.
\end{abstract}

\section{Introduction}

Staphylococcus (staphyle in Greek means bunch of grapes, kokkos meaning berry) are gram positive, catalase positive, coagulase positive, non motile, non sporing, occasionally capsulated spherical cocci, approximately 1 micrometre in diameter that occur in grape like clusters and are ubiquitous. ${ }^{1}$ Many of its species are known to be commensals in humans. ${ }^{1}$ Staphylococcus aureus is recognized as an epidemiologically important pathogen. ${ }^{2}$ These species are important as they can develop resistance against various classes of antibiotics (penicillin, methicillin etc.). ${ }^{1,3}$ One such identified antibiotic resistant pathogen is Methicillin Resistant Staphylococcus aureus (MRSA).

Earlier Staphylococcal infections were treated by penicillin but by 1944 , more than $90 \%$ of staphylococcal strains became resistant. ${ }^{4}$ This was due to the production of penicillinase $-\mathrm{a}$ 
plasmid mediated, inducible enzyme which splits the beta lactam ring of penicillin making the drug inactive. ${ }^{1}$ Another drug, methicillin was introduced in late $1950 \mathrm{~s}$ (1959) which too became ineffective by early $1960 \mathrm{~s}^{5}$ because of the alterations in penicillin binding protein, $\mathrm{PBP} 2 \mathrm{a}$ which is regulated by Staphylococcal cassette chromosomal mec gene (especially mec A). ${ }^{6}$ Such resistant strains were named MRSA. MRSA strains can be further divided into hospital acquired (HA-MRSA) and community acquired (CAMRSA). ${ }^{3}$ MRSA being resistant to all beta lactam antibiotics poses a great challenge in the treatment of its infections due to limited therapeutic options. ${ }^{7}$

Staphylococcus aureus is an important cause of a variety of pyogenic infections involving skin and soft tissue (folliculitis, furuncle, abscess, wound infections, carbuncle, impetigo, paronychia, less often cellulitis), musculoskeletal (osteomyelitis, arthritis, bursitis, pyomyositis), respiratory (tonsillitis, pharyngitis, sinusitis, otitis, bronchopneumonia, lung abscess, empyema, rarely pneumonia), central nervous system (abscess, meningitis, intracranial thrombophlebitis), endovascular (bacteraemia, septicaemia, pyemia, endocarditis), urinary tract infections. ${ }^{1}$

Some common toxin mediated staphylococcal diseases include: food poisoning, toxic shock syndrome, scalded skin syndrome. ${ }^{1}$

Epidemiological niches of Staphylococcus aureus are anterior nares. ${ }^{8}$ Other sites include axilla, umbilicus, perineal region and mammary folds. ${ }^{9}$ Healthy persons can act as carriers though they are at lesser risk of contracting infection. ${ }^{10}$ About $30-50 \%$ of healthy persons carry Staphylococcus in their nose and skin. ${ }^{11}$ hence making anterior nares the primary reservoirs and also the most consistent area from where they can be isolated. ${ }^{12}$ Since there is relative absence of human defences in this area, the staphylococcal cells flourish here and are capable of withstanding the local antibacterial defences. ${ }^{13}$

Health care workers (HCWs) constitute an important reservoir of Staphylococcus aureus. Nasal carriage of MRSA is a recognized risk factor for subsequent infection of endogenous origin. The rate of nasal carriage of Staphylococcus aureus among the HCWs from several studies ranges from 16.8 $56.1 \% .^{14-17}$ The colonization of MRSA in them can be attributed to exposure to patients infected with MRSA and also during the course of their work. ${ }^{18}$

Early and appropriate infection control measures (ICM) are key elements to reduce MRSA transmission and to control the hospital reservoir.

Reduction of antibiotic misuse, active surveillance, contact isolation, decolonization and improvement of hand hygiene compliance - are a few methods to control this superbug. 19

Strains against vancomycin (the drug of choice for MRSA) called as VRSA have now started to emerge ${ }^{1}$ which will lead to major therapeutic challenges by further narrowing the limited treatment options. Hence, preventive strategies need to be refurbished.

Our study is designed to determine the prevalence of nasal carriage of MRSA among HCWs. The study will thus help in identifying hidden reservoirs, establishing better antibiotic guidelines and sanitary protocol (hand hygiene practices, contact precautions, identifying previously colonized patients) for HCWs that will consequently aid in reducing the future incidence of nosocomial acquired MRSA. 


\section{Materials and Methods}

Study area: Tertiary health care centre, Government medical college, Rajnandgaon, Chhattisgarh.

Study type: Cross sectional

Study duration: $7^{\text {th }}$ July $2018-7^{\text {th }}$ September 2018 (2 months)

Sample size: 100 (using sample size formula, $\mathrm{N}=4 \mathrm{pq} / \mathrm{l}^{2}, \mathrm{p}=$ prevalence, $\mathrm{q}=100-\mathrm{p}, \mathrm{l}=$ allowable error)

The rate of nasal carriage of Staphylococcus aureus among healthcare workers from several studies ranges from $16.8-56.1 \%$.

$\mathrm{p}=33, \mathrm{q}=67, \mathrm{l}=10 \%$

$\mathrm{N}=88$ (Round off to 100 to reduce error)

Inclusion criteria: Health care workers from intensive care units, medicine wards, surgical wards, paediatrics wards, operating rooms, laboratory, orthopaedics wards. Health care workers included in the study are: doctors, nurses, technicians and class IV workers.

Exclusion criteria: 1)Health care workers with history of fever, upper respiratory tract infection, recent nasal surgery, use of nasal medication or antibiotic in the past one month. 2) Medical students were excluded.

Ethical considerations: Written Informed consent was obtained from all participants. The study was carried out after approval from Institutional Ethics Committee (Letter no./072018/GMC RJN/ I.E.C./2018 dated 06/07/2018).

Ethical considerations including privacy of personal data was considered in all steps of research.
Nasal swab collection: A sterile cotton swab was inserted into each nostril and rotated gently for 5 times on the anterior nares of the study participants. ${ }^{2}$. Nasal swabs were then transported in sterile test tubes to the laboratory.

Culture and identification: The swabs were inoculated on 5\% sheep blood agar and incubated at $37^{\circ} \mathrm{C}$ for 24 hours. Identification was done according to standard microbiological techniques. ${ }^{20}$

Antimicrobial susceptibility test and MRSA detection: The antimicrobial susceptibility patterns were tested by using modified Kirby Bauer method ${ }^{21}$ as per the Clinical and Laboratory Standards Institute guidelines. $^{22}$ The following antimicrobials were used - penicillin, tetracycline, clindamycin, chloramphenicol, cotrimoxazole, gentamycin, erythromycin, cefoxitin, ciprofloxacin (Hi Media labs, New Delhi, India). Colonies with an inhibition zone of less than or equal to $21 \mathrm{~mm}$ for cefoxitin were considered as methicillin resistant. ${ }^{22}$

Statistical analysis: The data was compiled in MS-Excel and then it was analysed and suitable statistical test was applied.

The decontamination processes were then initiated on MRSA positive health care workers as per standard norms.

\section{Results and Discussion}

During 2-months of study period, 100 health care workers were screened. Staphylococcus aureus colonisation was present in $21 \%$ (21 out of 100) HCWs and 13\% (13 out of 100) MRSA strains were isolated. Out of 21 S.aureus strains isolated, $13(61 \%, 13$ out of 21) strains were resistant to methicillin. 
Table 1 shows the distribution of Staphylococcus aureus and MRSA carriers among health care workers. Maximum percentage of Staphylococcus aureus and MRSA were found in nurses (8 MRSA, 11 S.aureus).

Table 2 shows the culture results of nasal swabs of healthcare workers. Staphylococcus aureus was found in 21 out of 100 samples. Table 3 shows sensitivity/ resistance profile of the S.aureus isolates. Maximum resistance is shown against penicillin, cefoxitin (13 out of 21 i.e. $61.90 \%$ ). Resistance to cefoxitin is shown in 13 S.aureus isolates. Maximum sensitivity is for ciprofloxacin (16 out of 21 i.e. $76.19 \%)$ (Graph 2).

Table.1 Distribution of Staphylococcus aureus and Methicillin Resistant Staphylococcus aureus carriers among healthcare workers

\begin{tabular}{|c|c|c|c|c|c|}
\hline Category & Male & Female & $\begin{array}{l}\text { Total No. } \\
\text { Sampled }\end{array}$ & S.aureus & $\begin{array}{l}\text { MRSA no. Positive } \\
\text { (carriage rate \%) }\end{array}$ \\
\hline Doctors & 12 & 18 & 30 & 2 & $0(0 \%)$ \\
\hline Staff nurses & 00 & 35 & 35 & 11 & $8(22.85 \%)(\mathrm{N}=35)$ \\
\hline Class IV & 11 & 4 & 15 & 4 & $3(20 \%)(\mathrm{N}=15)$ \\
\hline Technicians & 10 & 10 & 20 & 4 & $2(10 \%)(\mathrm{N}=20)$ \\
\hline Total & 33 & 67 & 100 & 21 & $13 \%(\mathrm{~N}=100)$ \\
\hline
\end{tabular}

Table.2 Culture results of nasal swabs of healthcare workers

\begin{tabular}{|l|l|l|}
\hline Culture results & Isolates & No./percentage \\
\hline Culture positive & S. aureus & $\mathbf{2 1}$ \\
\cline { 2 - 3 } & CONS & $\mathbf{3 5}$ \\
\cline { 2 - 3 } & Others & $\mathbf{1 6}$ \\
\hline Culture sterile & - & $\mathbf{2 8}$ \\
\hline Total & - & $\mathbf{1 0 0}$ \\
\hline
\end{tabular}

Table.3 Sensitivity/resistance profile of the S.aureus isolates

\begin{tabular}{|l|l|l|}
\hline Antibiotics & Sensitive no. $(\mathbf{\%})$ & Resistant no. (\%) \\
\hline Clindamycin & $15(71.42 \%)$ & $\mathbf{6}(\mathbf{2 8 . 5 7 \%})$ \\
\hline Chloramphenicol & $10(47.61 \%)$ & $\mathbf{1 1}(\mathbf{5 2 . 3 8 \% )}$ \\
\hline Erythromycin & $14(66.66 \%)$ & $\mathbf{7}(\mathbf{3 3 . 3 3 \%})$ \\
\hline Tetracycline & $12(57.14 \%)$ & $\mathbf{9}(\mathbf{4 2 . 8 5 \%})$ \\
\hline Gentamycin & $15(71.42 \%)$ & $\mathbf{6}(\mathbf{2 8 . 5 7 \%})$ \\
\hline Cefoxitin & $08(38.09 \%)$ & $\mathbf{1 3}(\mathbf{6 1 . 9 0 \%})$ \\
\hline Ciprofloxacin & $16(76.19 \%)$ & $\mathbf{5}(\mathbf{2 3 . 8 0 \%})$ \\
\hline Penicillin & $8(38.09 \%)$ & $\mathbf{1 3}(\mathbf{6 1 . 9 0 \%})$ \\
\hline Cotrimoxazole & $\mathbf{1 0}(\mathbf{4 7 . 6 1 \%})$ & $\mathbf{1 1}(\mathbf{5 2 . 3 8 \%})$ \\
\hline
\end{tabular}


Table.4 Comparative analysis with different studies

\begin{tabular}{|c|c|c|c|c|}
\hline $\begin{array}{l}\text { S.N } \\
\text { o. }\end{array}$ & Parameters & Present Study & Similar Studies & Contrast Studies \\
\hline \multirow[t]{6}{*}{1.} & S.aureus in & $21 \%$ & \multirow{6}{*}{$\begin{array}{l}22 \% \text { (Rutvi V. } \\
\text { et al.,.) } \\
31 \% \\
\text { (Mehdrad } \\
\text { Askarian } \\
\text { et al..,) }^{2}\end{array}$} & \multirow{5}{*}{$\begin{array}{l}\text { 0\%(Shobha } \\
\text { K. et al.,.) } \\
41.66 \% \\
(\text { Lovely } \\
\text { Gupta } \text { et al.,) })^{3}\end{array}$} \\
\hline & anterior nares & & & \\
\hline & & & & \\
\hline & & & & \\
\hline & & & & \\
\hline & & & & \\
\hline 2. & S.aureus \% category wise & & & \\
\hline \multirow[t]{6}{*}{ 2.a. } & Doctors & $6.66 \%$ & $15.2 \%$ (Rutvi & 40\%(Lovely \\
\hline & & $(2 / 30)$ & V. et.al $)^{7}$ & Gupta et al., $)^{3}$ \\
\hline & & & & $41 \%$ \\
\hline & & & & (Himadri \\
\hline & & & & Mandal \\
\hline & & & & et al., $)^{9}$ \\
\hline \multirow[t]{5}{*}{ 2.b. } & Nurses & $31.42 \%$ & $21.5 \%$ (Rutvi & $100 \%$ \\
\hline & & $(11 / 35)$ & et al.. $)^{7}$ & (Lovely \\
\hline & & & $45.97 \%$ & Gupta et al., $)^{3}$ \\
\hline & & & (Himadri & \\
\hline & & & Mandal et al., $)^{9}$ & \\
\hline 2.c. & Technicians & $20 \%(4 / 20)$ & $\begin{array}{l}12.64 \% \\
\text { (Himadri Mandal et } \\
\text { al., })^{9}\end{array}$ & $\begin{array}{l}42.85 \% \\
(\text { Lovely Gupta et } \\
\text { al.., })^{3}\end{array}$ \\
\hline \multirow[t]{2}{*}{ 2.d. } & Housekeepers & $26.66 \%$ & - & 75\% (Lovely \\
\hline & & $(4 / 15)$ & & Gupta et al., $)^{3}$ \\
\hline \multirow[t]{6}{*}{3.} & MRSA & $13 \%$ & $18.39 \%$ & $31.66 \%$ \\
\hline & positive \% & & (Himadri & (Lovely \\
\hline & & & Mandal & Gupta et al., $)^{3}$ \\
\hline & & & $5.3 \%$ & \\
\hline & & & (Mehrdad & \\
\hline & & & $\begin{array}{l}\text { Askarian et } \\
\text { al.., })^{2}\end{array}$ & \\
\hline 4. & $\begin{array}{l}\text { MRSA\% } \\
\text { category wise }\end{array}$ & & & \\
\hline 4.a. & Doctors & 0 & $\begin{array}{l}0 \% \\
(\text { Radhakrishna et al., })^{24}\end{array}$ & $\begin{array}{l}20 \% \text { (Lovely Gupta } \\
\text { et al., })^{3} 6.5 \%{ }^{7}\end{array}$ \\
\hline 4.b. & Nurses & $22.85(8 / 35)$ & $\begin{array}{l}6.1 \% \text { (Himadri Mandal } \\
\text { et al..) })^{9}\end{array}$ & $\begin{array}{l}75 \% \quad(\text { Lovely } \\
\text { Gupta et al. })^{3}\end{array}$ \\
\hline 4.c. & Technicians & $10(2 / 20)$ & $\begin{array}{l}2 \% \quad \text { (Himadri } \\
\left.\text { Mandal } \text { et }_{\text {al.., }}\right)^{9}\end{array}$ & - \\
\hline 4.d. & Housekeepers & $20(3 / 15)$ & $5.1 \%$ (Rutvi V. et al., $)^{7}$ & $\begin{array}{ll}\mathbf{5 0 \%} & \text { (Lovely } \\
\text { Gupta) } & \end{array}$ \\
\hline \multirow[t]{2}{*}{5.} & $\begin{array}{l}\text { Antibiotic susceptibility of } \\
\text { S.aureus . }\end{array}$ & & & \\
\hline & Maximum resistance & $\begin{array}{l}\text { Penicillin } \\
\text { cefoxitin }\end{array}$ & $\begin{array}{l}\text { Penicillin (Sharon } \\
\text { Rainy Rogharpi } e t \\
\text { al., })^{25}\end{array}$ & $\begin{array}{l}\text { Ciprofloxacin } \\
\text { (Yukti Sharma } \\
\text { et al.,.) })^{26}\end{array}$ \\
\hline
\end{tabular}


Graph.1 Distribution of S.aureus and MRSA carriers among HCWs

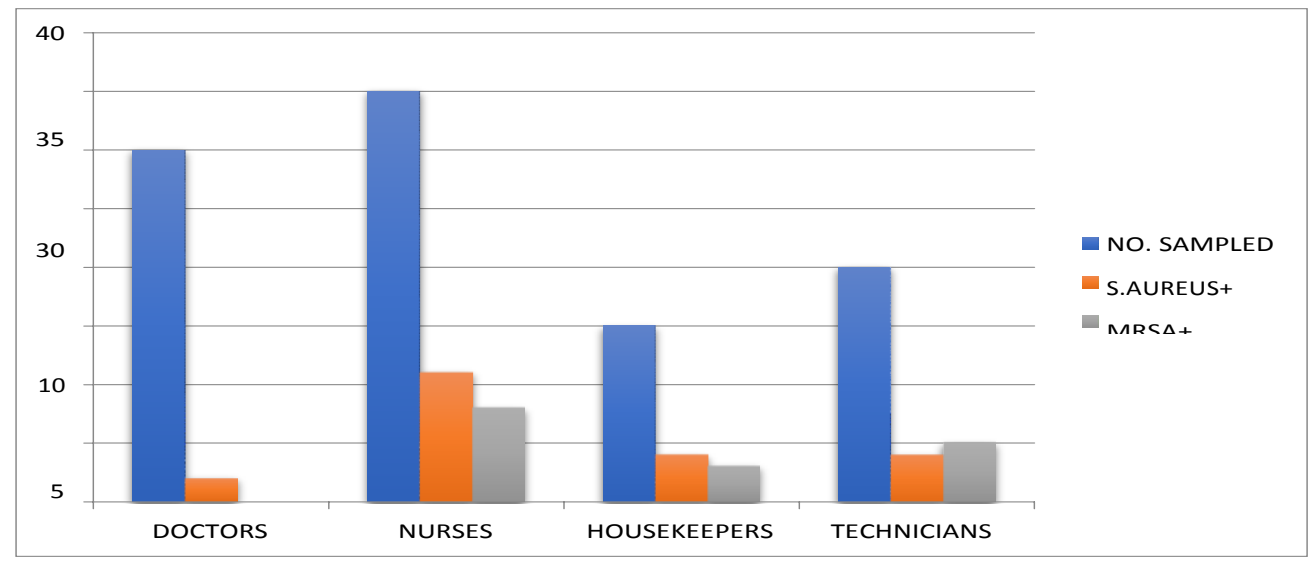

Graph.2 Sensitivity/resistance profile of S.aureus

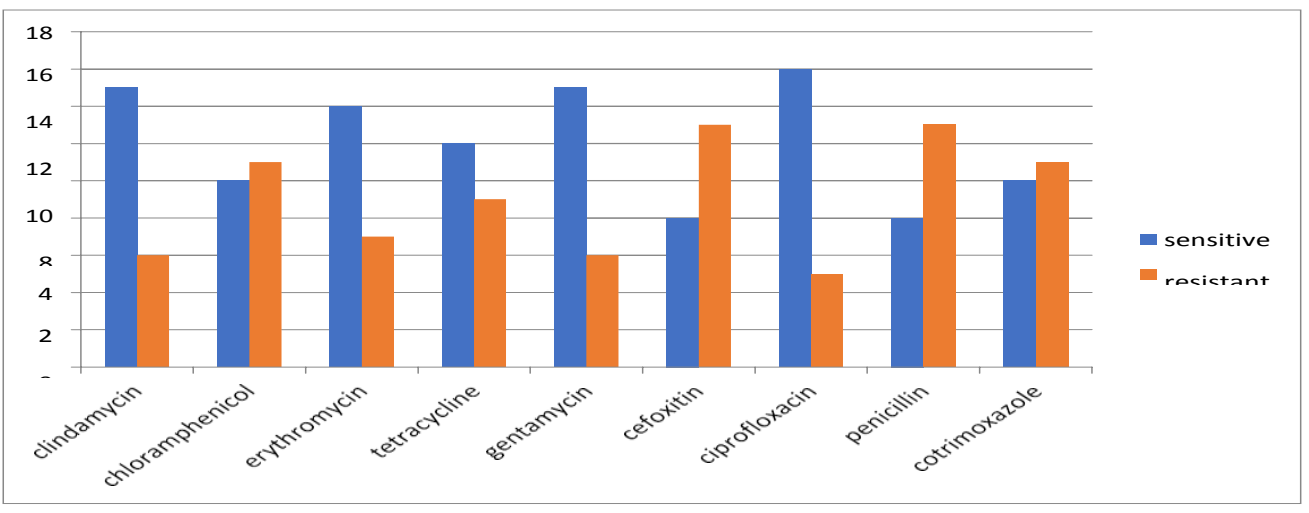

The prevalence of nasal carriage of MRSA among health care workers in Rajnandgaon has not yet been determined to date. This study shows $21 \%$ of healthcare workers were nasal carriers of Staphylococcus aureus. Of these $61 \%$ were MRSA (i.e. $13 \%$ of total). Studies with similar and contrast findings have been tabulated below.

The differences in the prevalence of nasal carriage of S.aureus is due to differences in the sample size, and different techniques.

In our study, the highest prevalence of MRSA is among nurses as they are in direct contact with the patients (Table 4).
However, no doctors showed MRSA colonization. This may be due to good infection control practice implementation.

High MRSA\% in Class IV workers may be due to their poor hygiene practices.

Relatively lesser MRSA prevalence was seen among technicians because of lack of direct contact with patients.

In conclusion, the present study found MRSA prevalence to be $13 \%$. Prevalence is higher among the nurses. Thus, proper infection control precautions should be employed to minimize carriage rate. Among the S.aureus isolates, maximum resistance is shown 
against penicillin, cefoxitin (13 out of 21 i.e. $61.90 \%)$. Maximum sensitivity is for ciprofloxacin (16 out of 21 i.e. $76.19 \%$ ). The key to prevent nosocomial infections is compliance with sanitary and antibacterial guidelines, alongwith periodical screening of HCWs.

\section{Recommendations}

Awareness among healthcare workers regarding judicious use of broad spectrum antibiotics and simple preventive measures including hand hygiene, can reduce transmission considerably.

Source of funding: Indian Council Of Medical Research-Short Term Studentship,

\section{Conflict of interest-Nil}

Ethical clearance- Study was approved from institutional ethical committee.

Acknowledgement: The authors are thankful to Faculties of Department of Microbiology, Government Medical College, Rajnandgaon (Chhattisgarh) India, for their support during study period.

\section{References}

1. R.Ananthanarayan, Jayaram P.CK.; Ananthanarayan and Panicker's textbook of Microbiology, 10th ed. India; 2017; 201- 209.

2. Mehdrad Askarian, Alihosein Zeinalzadeh, Aziz Japoni, Abdolvahab Alborzi, Ziad A. Memish. Prevalence of nasal carriage of Methicillin Resistant Staphylococcus aureus and its antibiotic susceptibility pattern in health care workers at Namazi hospital, Shiraz, Iran. International Journal of Infectious diseases. 2009.13, e241-e247

3. Lovely Gupta, Mohini Agarwal, Kumud Bala. Nasal carriage of Methicillin-Resistant Staphylococcus aureus (MRSA) in health care workers and healthy individuals in a Tertiary care hospital. IJPBS; 2015; 5(4);7-17.
4. Chakraborty S.P., KarMahapatra S., Bal M. and Roy S., Isolation and Identification of Vancomycin-Resistant Staphylococcus aureus from Post-Operative Pus Sample. Al Ameen Journal of Medical Sciences, 2011; 4 (2):152 168.

5. Enright MC, Robinson DA, Randle G, Feil EJ, Grundmann H, Spratt BG. The evolutionary history of methicillin-resistant Staphylococcus aureus (MRSA). Proc Natl Acad Sci USA 2002; 99: 7687-92.

6. Hiramatsu K. Vancomycin resistance Staphylococcus aureus: a new model of antibiotic resistance. Lancet. 2001. 1, 147155.

7. Rutvi V, Sangeeta PD, Sima BK, Piyush PA. Nasal Carriage Rate of Methicillin-Resistant Staphylococcus aureus (MRSA) among Civil Hospital Healthcare workers. Int $\mathbf{J}$ Med. Public Health. 2016; 6(4):180-3.

8. Peacock SJ, Justice A, Griffiths D, DeSilva GDI, Kantzanuo MN, Crook D etal. Determinants of Acquisition and Carriage of Staphylococcus aureus in Infancy. J Clin Microbiol. December 2003; 41(12): 5718-25.

9. Himadri Mandal, Indrajit Gupta, Poulami Nandi, Purbasha Ghosh, Saraswati Chattopadhyay, G.D. Mitra. Nasal screening of health care workers for nasal carriage of Methicillin Resistant Staphylococcus aureus, Vancomycin resistance Staphylococcus aureus and prevalence of nasal colonization with Staphylococcus aureus in Burdwan Medical College and hospital. International journal of contemporary medical research 2016; 3(11); 3342-3346.

10. Foster TJ. The Staphylococcus aureus "superbug". J Clinical Invest. 2004; 114:169396. Deresinski S. Methicillin- Resistant Staphylococcus aureus: an evolutionary, epidemiologic, and therapeutic odyssey. Clin Infect Dis. 2005;40:562-73.

11. Graham P.L., Lin S.X., Larson E.L., A U.S. population based survey of Staphylococcus aureus colonization. Annals of Internal medicine, 2006,144, 318-325.

12. Williams, R. E. O. 1963. Healthy carriage of Staphylococcus aureus: its prevalence and importance. Bacteriol. Rev. 27:56- 71 KluytmansJ, Alexvan Belkum, Verbrugh H. Nasal carriage of Staphylococcus aureus: 
Epidemiology, underlying mechanisms, and associated risk factors.Clinical Microbiology Reviews 1997:10(3);505-520.

13. Dan, M, YMoses, F Poch, J Asherov, R Gutman. Carriage of Methicillin-resistant Staphylococcus aureus by non- hospitalized subjects in Israel. Infection.1992; 20: 332-35.

14. Duncan IBR, Collins AM, Neelin EM, Roy TE. Nasal carriage of Staphylococcus pyogenes by student nurses. Can. Med. Assoc. J. 1957 December 1; 77(11):1001-09.

15. McAnally TP, Lewis MR, Brown DR. Effect of rifampin and bacitracin on nasal carriers of Staphylococcus aureus. Antimicrob Agents Chemother. 1984 April; 25(4): 22-26.

16. Paul MO, Lamikanra A, Aderibigbe DA. Nasal carriers of coagulase-positive staphylococci in a Nigerian hospital community. Trans. R. Soc. Trop. Med. Hyg. 1982; 76(3): 319-23.

17. Akoua Koffi C, Dje K, Toure R, Guessennd $\mathrm{N}$, Acho B, Faye Kette $\mathrm{H}$, et al., Nasal carriage of methicillin-resistant Staphylococcus aureus among healthcare personnel in Abidjan (Cote d'Ivorine). Dakar Med. 2004; 49: 70-74.

18. Marimuthu et al., The effect of improved hand hygiene on nosocomial MRSA control Antimicrobial Resistance and Infection Control 2014, 3: 34.

19. Collee JG, Fraser AG, Marmion BP, Simmons A. Mackie and McCartney Practical Medical Microbiology, 1999, 14th ed. New York: Churchill Livingstone;. Bauer AW, Kirby WM, Sherris JC, Turck M. Antibiotic susceptibility testing by standardized single disk method. Am J Clin Pathol 1966; 45: 4936.

20. Clinical and Laboratory Standard Institute. Performance Standard for Antimicrobial Susceptibility Testing: Eighteenth Informational Supplement; M100S. Wayne, PA, USA: CLSI; 2017.

21. Shobha K.L., Rao PS, Thomas J. Survey of Staphylococcus isolates among hospital personnel, environment and their antibiogram with special emphasis on Methicillin Resistance. Indian J. Med Microbiol. 2005; 23(3): 186-88.

22. Radhakrishna M, Monalisa D'Souza. Subbannayya Kotigadde, Vishwas Saralaya K. ShashidarKotian M. Prevalence of Methicillin Resistant Staphylococcus aureus Carriage amongst Health Care Workers of Critical CareUnits in Kasturba Medical College Hospital. Mangalore. India. Journal of Clinical and Diagnostic Research. 2013:7:2697-2700

23. Sharon Rainy Rongharpi, Naba Kumar Hazarika, Hitesh Kalita. The prevalence of nasal carriage of Staphylococcus aureus among health care workers at a tertiary care centre hospital in Assam with special reference to MRSA. Journal of clinical and diagnostic research. 2013. February; vol. 7(2); 257- 260.

24. Yukti Sharma, Sanjay Jain, Harshvardhan Singh, and Vasudha Govil. Staphylococcus aureus: Screening for nasal carriers in a community setting with special reference to MRSA. 2014. Scientifica.

\section{How to cite this article:}

Kausar Rawani and Siddharth Pimpalkar. 2020. Screening of Nasal MRSA Carriage among Health Care Workers at a Tertiary Care Centre in Chhattisgarh at Rajnandgaon District. Int.J.Curr.Microbiol.App.Sci. 9(12): 1467-1474. doi: https://doi.org/10.20546/ijcmas.2020.912.174 